\title{
Translocation (8;21) in Acute Nonlymphocytic Leukemia Delineated by Chromosomal In Situ Suppression Hybridization
}

\author{
Susanne Popp, Anna Jauch, Jing Ying Qiu, \\ Barbara Smialek, Thomas Cremer, \\ and Reinhard Becher
}

\begin{abstract}
In situ suppression hybridization with recombinant bacteriophage DNA libraries for chromosomes 8 and 21 was performed in two cases of acute nonlymphocytic leukemia, type $F A B$ $M 2$. In both cases, cytogenetic analysis by conventional G-banding revealed $t(8 ; 21)(q 22 ; q 22)$. In situ suppression hybridization was able to prove the reciprocal nature of the translocation in both cases by identifying the terminal end of chromosome 21 translocated to the derivative chromosome 8q-.
\end{abstract}

\section{INTRODUCTION}

Nonrandom chromosomal anomalies, in addition to phenotyping, have been well accepted as an important feature in the subclassification of acute nonlymphocytic leukemias (ANLL). Therefore, it was proposed to replace the conventional FAB (French, American, British) nomenclature [1] with a new convention, designated as the MIC classification, which would include morphology, immunophenotyping, and chromosomal anomalies [2]. Even though the significant impact of chromosomal findings for prognosis has been accepted, their broader application in clinical practice has been hampered by the high expenditure necessary for detailed banding studies, which are time consuming, need skilled personnel, and, so far, cannot be automated. Therefore, there remains a strong demand for new techniques to simplify, accelerate, and improve the detection of specific chromosomal anomalies in malignancies.

A recent modification of non-radioactive in situ hybridization (for review, see [3]), called chromosome painting [4] or chromosomal in situ suppression (CISS) hybridization [5], has provided a new tool with which to overcome some of the shortcomings of conventional cytogenetic analyses. Using recombinant DNA libraries established from sorted human chromosomes, this procedure has made possible the specific delineation ("painting") of individual human chromosomes. In particular, translocations derived from painted chromosomes can be easily recognized [4, 6-8]. The sensitivity of this approach, however, may be limited by the size of the translo-

From the Innere Universitatsklinik (Tumorforschung), West German Cancer Center Essen: and Institute of Human Genetics and Anthropology (S. P., A. J., T. C.), University of Heidelberg, Germany.

Address reprint requests to: Reinhard Becher, M.D., Innere Universitäts- und Poliklinik (Tumorforschung), Westdeutsches Tumorzentrum, Hufelandstr. 55, D-4300 Essen 1, FRG.

Received September 7, 1990; accepted October 8, 1990. 
cated part of a painted chromosome, depending on the localization of the breakpoint. To study this question and further demonstrate the potential of CISS hybridization for tumor cytogenetics, we selected $t(8 ; 21)$, a nonrandom chromosomal anomaly in ANLL. In this case the translocated part of chromosome 8 is relatively large, whereas the terminal region of $21 q$ reciprocally translocated to the derivative chromosome $8 q-$ is small, frequently escaping detection in conventional banding studies.

\section{MATERIALS AND METHODS}

\section{Patients and Cytogenetic Methods}

Two female patients aged 59 years (patient 1) and 21 years (patient 2) were diagnosed with typical ANLL-M2 in March and May 1989, respectively. Both patients were alive and in continuing complete remission at the time of this study. At the time of diagnosis, conventional G-banded karyotypes were established after short-term treatment with trypsin, and evaluated according to the ISCN nomenclature [9].

\section{DNA Libraries and CISS Hybridization}

Bacteriophage DNA libraries from sorted human chromosomes 8 and 21 were obtained from the American type culture collection (\#8: LL08NS02; \#21: LA21NS01). Amplification of these libraries, isolation of the bacteriophage DNA, chemical modification by nicktranslation with biotin-11-dUTP, and CISS hybridization were carried out as described in detail elsewhere [5]. Biotinylated DNA sequences were detected by using fluoresceine-isothiocyanate (FTTC)-conjugated avidin (green fluorescence). For signal amplification, the protocol of Pinkel et al. [10] was used. Metaphase chromosomes were counterstained with propidium iodide (PI, red fluorescence) and 4,6-Diamidino2-phenylindol-dihydrochlorid (DAPI, blue fluorescence) and examined with a Zeiss photo microscope III equipped with epifluorescence. Pictures were taken at high numerical aperture with Agfachrome 1000 ASA diapositive films.

\section{RESULTS}

G-banding of leukemic cells at the time of diagnosis revealed $t(8 ; 21)$ in all metaphases of patients 1 and 2 with breakpoints in 8q22 and 21q22. It was not clear, however, from these analyses whether the terminal band of chromosome 21 was lost or whether the translocation was reciprocal. In addition, patient 1 showed an interstitial deletion $8 q-$, whereas both patients lacked one $X$ chromosome in about $25 \%$ of the metaphases.

In both cases, CISS hybridization with a chromosome 8 DNA library revealed the translocation of chromosome 8 material to a small acrocentric chromosome (Fig. 1a), which was further identified as chromosome 21 by fluorescence banding with DAPI (not shown). The reciprocal nature of the translocation was demonstrated by CISS hybridization with a chromosome 21 DNA library, which clearly delineated a distinct double spot of yellow-green fluorescent chromosome 21 material on the long arm of the derivative chromosome $8 \mathrm{q}-$ (Fig. 1b).

\section{DISCUSSION}

In this study, we show that painting of chromosomes 8 and 21 provides a reliable tool for the specific delineation of reciprocal $t(8 ; 21)(q 22 ; q 22)$ in two cases of ANLL. In particular, the terminal chromatid material of chromosome 21 translocated recipro- 


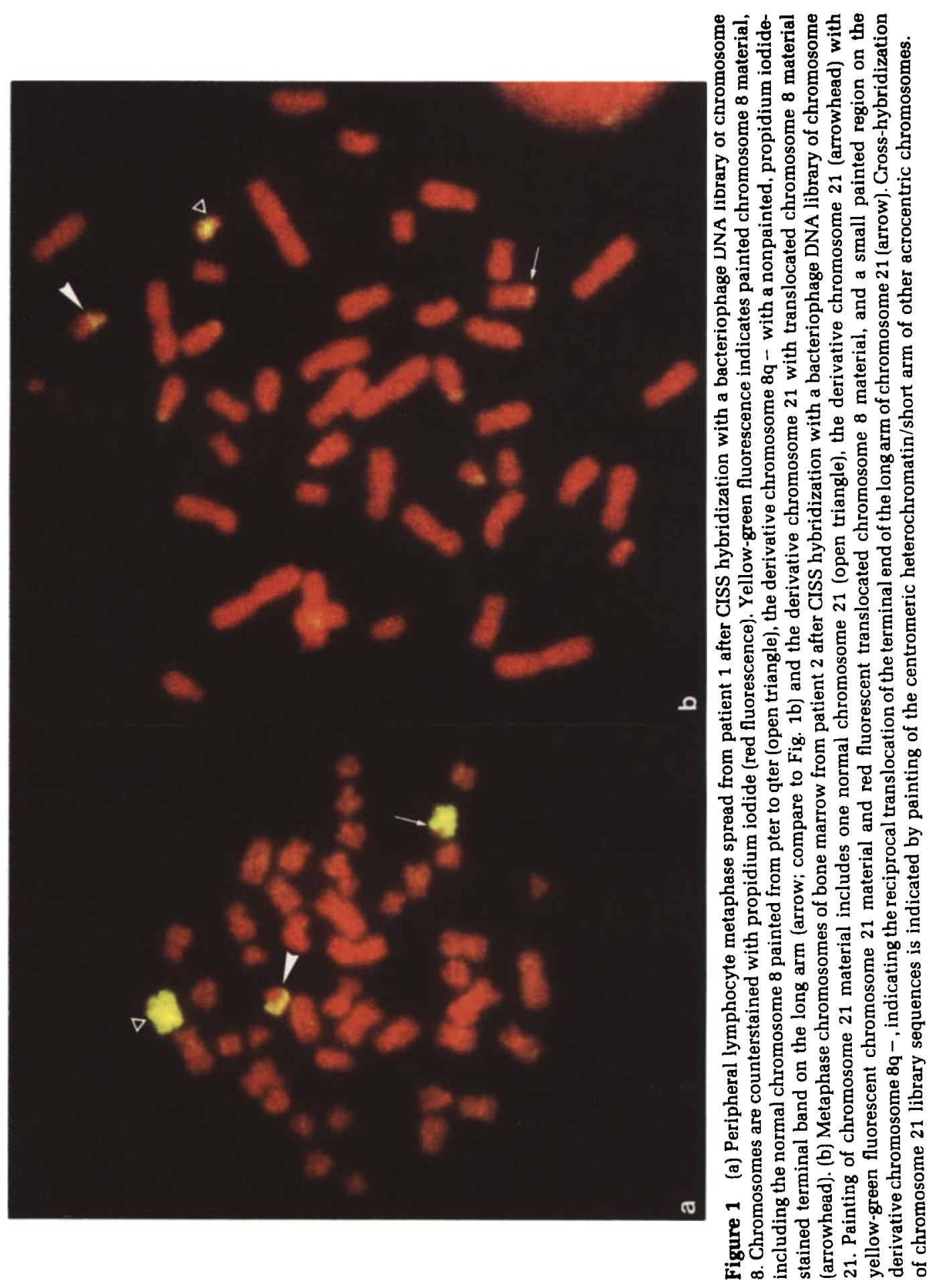


cally to the derivative chromosome $8 \mathrm{q}-$ was unequivocally detected. This material mostly escapes detection after G-banding analysis. Whereas R-banding may be used to clarify the reciprocal nature of some $t(8 ; 21)$ cases, identification of the translocation depends on sufficiently elongated chromosomes and does not allow a specific identification. In contrast, chromosome painting may be used for the unequivocal identification even in metaphases with rather condensed chromosomes. Accordingly, CISS hybridization with DNA libraries from sorted chromosomes may be recommended as a proper tool for detecting translocations of a few DNA megabases in cases where chromosome banding patterns do not allow a distinctive differential diagnosis between deletion or translocation [8]. Painting of whole chromosomes using DNA libraries from sorted chromosomes provides the advantage that translocations involving any material from the painted chromosome can be detected. CISS hybridization of appropriate cosmid or YAC clones may be used for the identification of still smaller translocations, deletions, or inversions, as well as for the precise definition of breakpoints $[11-19]$.

Part of this work was supported by grants of the Deutsche Forschungsgemeinschaft given to R. B. (SFB 102, project A10, Essen) and T. C. (Cr59/10-1).

\section{REFERENCES}

1. Fourth International Workshop on Chromosomes in Leukemia, 1982. (1984) Cancer Genet Cytogenet 11:251-360.

2. Second MIC cooperative study group (1988) Morphologic, immunologic and cytogenetic (MIC) working classification of the acute myeloid leukaemias. Br J Haematol 68:487-494.

3. Lichter P, Ward DC (1990): Is non-radioactive in situ hybridization finally coming of age? Nature 345:93-95.

4. Pinkel D, Landegent J, Collins C, Fuscoe J, Segraves R, Lucas J, Gray JW (1988): Fluorescence in situ hybridization with human chromosome specific libraries: detection of trisomy 21 and translocations of chromosome 4. Proc Natl Acad Sci USA 85:9138-9142.

5. Lichter P, Cremer C, Borden J, Manuelidis L, Ward DC (1988): Delineation of individual human chromosomes in metaphase and interphase cells by in situ suppression hybridization using recombinant DNA-libraries. Hum Genet 80:224-234.

6. Cremer T, Lichter T, Borden J, Ward DC, Manuelidis L (1988): Detection of chromosome aberrations in metaphase and interphase tumor cells by in situ hybridization using chromosome specific library probes. Hum Genet 80:235-246.

7. Cremer T, Popp S, Emmerich P, Lichter P, Cremer C (1990): Rapid metaphase and interphase detection of radiation-induced chromosome aberrations in human lymphocytes by chromosomal suppression in situ hybridization. Cytometry 11:110-118.

8. Jauch A, Daumer C, Lichter P, Murken J, Schroeder-Kurth T, Cremer T (1990): Chromosomal in situ suppression hybridization of human gonosomes and autosomes and its use in clinical cytogenetics. Hum Genet 85:145-150.

9. ISCN (1985): An International System for Human Cytogenetic Nomenclature, DG Harnden, HP Klinger, eds.; published in Collaboration with Cytogenetics and Cell Genetics (Karger, Basel, 1985); also in Birth Defects: Original Article Series, Vol. 21, No. 1 (March of Dimes Birth Defects Foundation, New York, 1985).

10. Pinkel D, Straume T, Gray JW (1986): Cytogenetic analysis using quantitative, high-sensitivity, fluorescence hybridization. Proc Natl Acad Sci USA 83:2934-2938.

11. Landegent JE, Jansen in de Wal N, Dirks RW, Baas F, van der Ploeg M (1987): Use of whole cosmid cloned genomic sequences for chromosomal localization by non-radioactive in situ hybridization. Hum Genet 77:366-370.

12. Fuscoe JC, Collins CC, Pinkel D, Gray JW (1989): An efficient method for selecting uniquesequence clones from DNA-libraries and its application to fluorescent staining of human chromosome 21 using in situ hybridization. Genomics 5:100-109.

13. Lichter P, Tang CC, Call K, Hermanson G, Evans GA, Housman D, Ward DC (1990): High 
resolution mapping of human chromosome 11 by in situ hybridization with cosmid clones. Science 247:64-69.

14. Lichter P, Jauch A, Cremer T, Ward DC (1990): Detection of Down syndrome by in situ hybridization with chromosome 21 specific DNA probes. In: Molecular genetics of chromosome 2 and Down syndrome. Proceedings of the 1989 Science Symposium of the National Down's Syndrome Society. D. Patterson, Ed., Wiley-Liss, Inc., New York, pp. 69-78.

15. Ried T, Mahler V, Vogt P. Blonden L, van Ommen GJB, Cremer T, Cremer M (1990): Carrier detection by in situ suppression hybridization with cosmid clones of the Duchenne/Becker muscular dystrophy (DMD/BMD)-locus. Hum Genet, 85:581-586.

16. Lux SE, Tse WT. Menninger JC, John KM, Harris P. Shalev O, Chilcote RR, Marchesi SL. Watkins PC, Bennett V, Mc:Intosh S, Collins FS. Francke U, Ward DC, Forget BG (1990): Hereditary sperocytosis associated with deletion of human erythrocyte ankyrin gene on chromosome 8. Nature 345:736-739.

17. Dauwerse JG, Kievits T, Beverstock GC, van der Keur D, Smit E, Wessels HW, Hagemeijer A, Pearson PL, van Ommen GJB, Breuning MH (1990): Rapid detection of chromosome 16 inversion in acute nonlymphocytic leukemia, subtype M4: regional localization of the breakpoint in 16p. Cytogenet Cell Genet 53:126-128.

18. Kievits T, Dauwerse JG, Wiegant J, Devilee P. Breuning MH, Cornelisse CJ, van Ommen GJB, Pearson PL (1990): Rapid subchromosomal localization of cosmids by nonradioactive in situ hybridization. Cytogenet Cell Genet 53:134-136.

19. Wada M, Little RD, Abidi F, Porta G, Labella T, Cooper T, delle Valle G, d'Urso M, Schlessinger D (1990): Human Xq24-Xq28: Approaches to mapping with yeast artificial chromosomes. Am J Hum Genet 46:95-106. 